\title{
Chronic inflammatory demyelinating polyneuropathy mimicking a lumbar spinal stenosis syndrome
}

\author{
L Ginsberg, A D Platts, P K Thomas
}

\begin{abstract}
A patient with chronic inflammatory demyelinating polyneuropathy (CIDP) established by biopsy developed cauda equina symptoms due to swelling of the nerve roots in the lumbar spinal canal. Magnetic resonance imaging of the lumbar spine showed profoundly thickened nerve roots from the level of the conus medullaris, filling the caudal thecal sac. Immunosuppressant treatment produced partial clinical and radiological resolution. This case shows that spinal compressive syndromes may occur in acquired hypertrophic neuropathies as well as in hereditary motor and sensory neuropathy and expands the range of the clinical presentation of CIDP.
\end{abstract}

(F Neurol Neurosurg Psychiatry 1995;59:189-191)

Keywords: chronic inflammatory demyelinating polyneuropathy; lumbar spinal canal; magnetic resonance imaging

Widespread nerve enlargement may occur in leprosy, amyloid neuropathy, chronic inflammatory demyelinating polyneuropathy (CIDP), acromegaly, neurofibromatosis, Refsum's disease, and hereditary motor and sensory neuropathy (HMSN) types I and III. ${ }^{1}$ In hypertrophic neuropathy, enlargement of the proximal nerve roots has been reported to produce spinal compression syndromes, ${ }^{2-14}$ although this complication has generally been associated with the hereditary causes. ${ }^{14}$ We describe a patient with CIDP who developed a lumbar "spinal stenosis" syndrome due to swollen nerve roots within the caudal theca.

London, UK theca.

L Ginsberg

P K Thomas

Department of Radiology, Royal Free Hospital, London, UK A D Platts

Correspondence to: Dr L Ginsberg, Department f Clinical Neurosciences, Royal Free Hospital School of Medicine, Rowland Hill Street, London NW3 2PF UK.

Received 10 February 1995 and in revised form 2 May 1995

Accepted 9 May 1995 showed a diffuse demyelinating polyneuropathy. She was treated with oral corticosteroids, with some improvement. In 1987, her back pain recurred. There was a reduction in motor nerve conduction velocity $(25 \mathrm{~m} / \mathrm{s})$ and a CSF protein concentration of $1.4-1 \cdot 8 \mathrm{~g} / \mathrm{l}$, grossly enlarged nerve roots were seen in the lumbar thecal sac at myelography. Corticosteroid treatment was again beneficial.

In 1992, she experienced a severe recurrence of lumbar pain, worse with walking or sitting for extended periods, and relieved by rest in a standing position. She also described numbness and burning paraesthesiae over the anterior aspect of the left thigh, with mild numbness distally in both lower limbs. There was no weakness, bladder and bowel function were normal, and there were no symptoms in the upper limbs or symptoms referable to the cranial nerves. Examination showed normal cranial nerves and no abnormal motor signs. Tendon reflexes were absent apart from a sluggish right biceps jerk; the plantar responses were flexor. There was mild subjective impairment for light touch and pinprick distally in all four limbs. Vibration sense and joint position sense were normal. Peripheral nerves were not thickened.

Routine haematological and biochemical investigations were normal with no evidence of a serum paraprotein. An autoantibody screen was negative. DNA analysis did not show the duplication on the short arm of chromosome 17 associated with HMSN Ia. Nerve conduction studies showed a generalised sensorimotor neuropathy with patchy slowing (to $20 \mathrm{~m} / \mathrm{s}$ motor nerve conduction velocity) and conduction block. Magnetic resonance imaging of the lumbar spine showed that the theca was almost completely occupied by enlarged nerve roots from T12 to L5. There was abnormal enhancement of the thickened nerve roots after intravenous gadolinium diethylene triamine penta-acetic acid (DTPA) (figure A, B). A sural nerve fascicular biopsy showed demyelination with minor hypertrophic changes, moderate loss of myelinated nerve fibres, and scattered infiltration with CD4 and CD8 lymphocytes. The appearances were those of CIDP.

The patient was treated with $300 \mathrm{mg}$ cyclosporin A twice daily, with relief of her symptoms suggestive of lumbar spinal stenosis. Repeat MRI one year after starting 


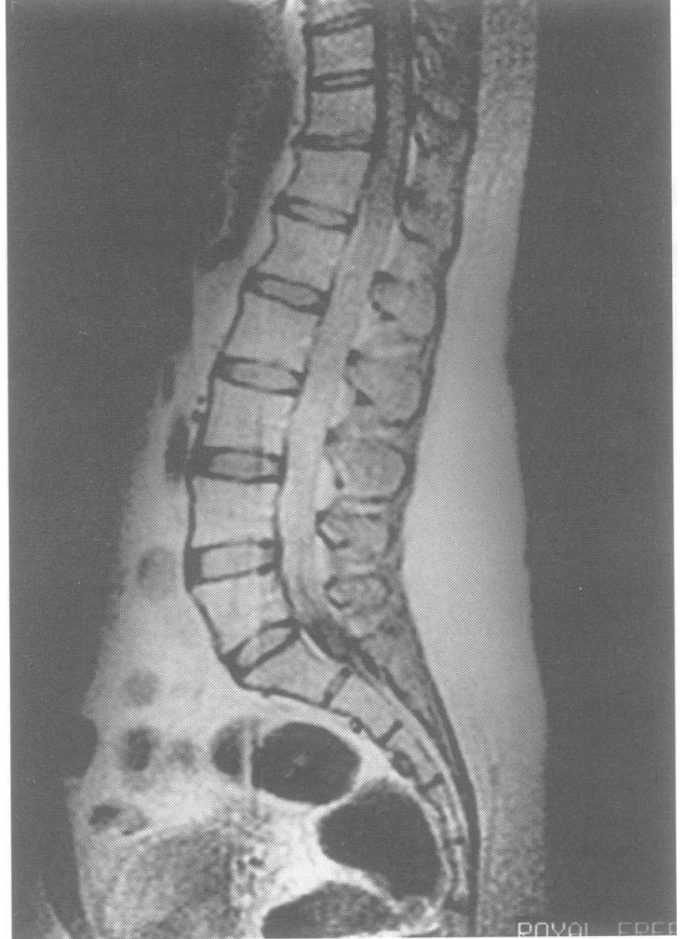

$A$

T1 weighted spin echo images of the lumbar spine. (A) sagittal, (B) axial L3/4 both post-gadolinium

pretreatment, showing the thecal sac filled with abnormal enhancing enlarged nerve roots, virtually obliterating the CSF space from $T 12$ to $L 5$. (C) axial L3/4 postgadolinium post-treatment (one year with cyclosporin $A$ ), showing persistent thickening of lumbosacral nerve roots but abnormal enhancement no longer apparent.

immunosuppressant treatment showed that the spinal canal remained occupied by abnormal soft tissue from the lower thoracic region to L5/S1 compatible with persistent thickening of the lumbosacral nerve roots. Abnormal enhancement of these roots after intravenous gadolinium DTPA was no longer apparent, however (figure $\mathrm{C}$ ).

\section{Discussion}

Differentiating between CIDP and HMSN is a common diagnostic problem in clinical neurology. In this patient's case, a diagnosis of HMSN had previously been entertained despite the negative family history, partial response to corticosteroids, and raised CSF protein concentration. This may in part have been because clinical presentations similar to the patient's, with a cauda equina syndrome due to swollen nerve roots in the lumbar theca, have only previously been described in detail in the context of hereditary hypertrophic neuropathies. ${ }^{14}$ The detailed investigation of this patient, in particular the 1992 nerve conduction and biopsy findings, pointed towards CIDP, however, as the correct underlying diagnosis. Further support was provided by the imaging. Thus although the actual nerve enlargement was non-specific, pathological enhancement of the roots after intravenous gadolinium DTPA, indicative of breakdown of the blood-nerve barrier,

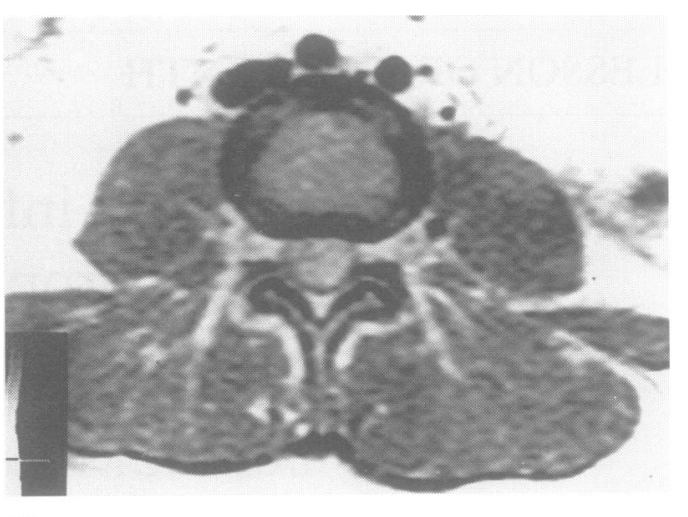

B

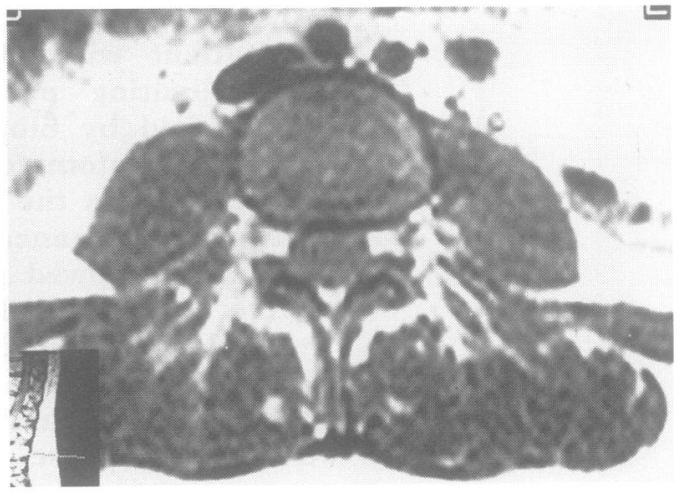

C

suggested inflammation. ${ }^{15}$ Finally, the response to immunosuppressant treatment, both clinically and in terms of resolution of the abnormal enhancement on MRI, was consistent with CIDP rather than HMSN.

Immunosuppressant treatment was chosen in 1992, as opposed to a further course of corticosteroids, as these had previously only produced a partial response, and also in view of the patient's borderline hypertension and moderate obesity. In the absence of muscle weakness or severe sensory loss, treatment with plasma exchange or high dose intravenous immunoglobulin was judged inappropriate and cyclosporin $A$ was thought to be more rapidly acting and effective than azathioprine. ${ }^{16}$

In view of the relative predilection of the neuropathological changes of CIDP for the proximal portions of nerves, ${ }^{17}$ it is perhaps surprising that there is little published reference to CIDP, as opposed to HMSN, producing spinal compression syndromes. Indeed, the absence of palpable peripheral nerve thickening in our patient in the context of such pronounced spinal root enlargement would have been unexpected in HMSN.

The bias in the medical literature towards HMSN rather than CIDP as a cause of spinal compression may in part stem from the time when these conditions were nosologically less distinct, patients being given the generic diagnosis of "progressive hypertrophic interstitial neuropathy of Dejerine and Sottas". ${ }^{1}$ Many of the case reports of spinal compression syndromes from that era, and indeed 
subsequently, may have been examples of CIDP, as nerve biopsy abnormalities were non-specific, and a family history of neurological disease was often absent ${ }^{2-47101213}$ or at best questionable. ${ }^{51114}$ Our patient shows definitively that spinal compression syndromes may occur in acquired hypertrophic neuropathies as well as in HMSN and expands the spectrum of the clinical presentation of CIDP.

We thank Dr R H M King and Miss J Workman for assistance with the histopathological studies. 1 Thomas PK, Lascelles RG, Stewart G. Hypertrophic neuropathy. In: Vinken PJ, Bruyn GW, eds. Handbook of clinical neurology, Vol 21, system disorders and atrophies.

2 Bruns G. Zur Kenntnis der hypertrophischen Neuritis (Roussy-Cornil). Beitr Path Anat 1951;111:407-18.

3 Roger H, Poursines Y, Gallais P, Roger J. Polynévrite hypertrophique de l'adulte (nonfamiliale) avec paraparésie spasmodique. Rev Neurol 1952;86:695-8.

4 Lewtas NA, Dimant $S$. The diagnosis of hypertrophic interstitial polyneuritis by myelography. $f$ Fac Radiol 1957;8:276-9.

5 Symonds CP, Blackwood W. Spinal cord compression in hypertrophic neuritis. Brain 1962;85:251-60.

6 Andermann F, Lloyd-Smith DL, Mavor H, Mathieson G. Observations on hypertrophic neuropathy of Dejerine and Sottas. Neurology 1962;12:712-24.
7 Hinck VC, Sachdev NS. Myelographic findings in hypertrophic interstitial neuritis. AfR Am F Roentgenol 1965; 95:947-8.

8 Bellon EM, Kaufman B, Tucker ME. Hypertrophic neuropathy: plain film and myelographic changes. Radiology 1972;103:319-22.

9 Kremenitzer M, Ager PJ, Zingesser LH. Myelographic evidence for nerve root enlargement in a case of Charcot-Marie-Tooth disease. Neuroradiology 1976;11: 165-7.

10 Hammerschlag SB, Adelman LS, Marcus EM, Wolpert SM. Cervical myelographic changes in hypertrophic interstitial polyneuropathy. Ann Neurol 1977;2:83-4

11 Carlin L, Biller J, Challa V, Riela A. Hypertrophic neuropathy with spinal cord compression. Surg Neurol 1982;18:237-40.

12 Miura T, Hirabuki N, Imakita S, Harada $K$, Kawai R, Mitomo M, Takahashi M. Radiological findings in a case of Charcot-Marie-Tooth disease $\mathrm{Br} f \mathrm{f}$ Radiol 1985;58:1017-20.

13 Morano JU, Russell WF. Nerve root enlargement in Charcot-Marie-Tooth disease: CT appearance. Radiology 1986;161:784

14 Rosen SA, Wang H, Cornblath DR, Uematsu S, Hurko O. Compression syndromes due to hypertrophic nerve roots in hereditary motor sensory neuropathy type 1 . in hereditary motor sen

15 Crino PB, Grossman RI, Rostami A. Magnetic resonance imaging of the cauda equina in chronic inflammatory demyelinating polyneuropathy. Ann Neurol 1993;33: 311-3.

16 Pollard JD. Chronic inflammatory demyelinating polyneuropathy. In: McLeod JG, ed. Baillière's clinical neurology: inflammatory neuropathies. London: Baillière Tindall, 1994:107-27

17 Prineas JW. Pathology of inflammatory demyelinating neuropathies. In: McLeod JG, ed. Baillière's clinical neurology: inflammatory neuropathies. London: Baillière Tindall, 1994:1-24.

\section{A note on Claude Bernard-Horner's syndrome continued from page 188}

acquired a lifelong interest in eye diseases. He worked with von Graefe who became his close friend. In 1862 he was appointed Professor of ophthalmology in his home town. Apart from his studies of cervical sympathetic paralysis, he described a man with red-green colour blindness who had transmitted the disorder to his male grandchildren through an unaffected daughter: establishing sex linked transmission. Analby, Hull HU10 7BG, UK
1 Bernard C. Sur les effets de la section de la portion céphalique du grand sympathique. Comptes Rendus. Société de Biologie, Paris 1852;4:168-9.

2 Pourfour du Petit F. Mémoire dans lequel il est démonstré que les nerfs intercosteaux fournissent des rameaux qui portent des esprits dans les yeux. Histoire de l'Académie Royal des Sciences, Paris, Mémoires 1727;1-19.

3 Mitchell SW, Morehouse GR, Keen WW. Gunshot wounds and other injuries to nerves. Philadelphia: Lippincott, 1864.

4 Hare ES. Tumour involving certain nerves. London Medical Gazette 1838;23:16-8.

5 Horner F. Ueber eine Form von Ptosis. Klinische Monatsblätter für Augenheilkunde 1869;7:193-8, translated by JF Fulton. ${ }^{\circ}$

6 Fulton JF. Horner and the syndrome of paralysis of the cervical sympathetic. Arch Surg 1929;18:2025-39. 